\title{
PENGEMBANGAN PERANGKAT PEMBELAJARAN KURIKULUM 2013 DI SEKOLAH DASAR
}

\author{
Ibadullah Malawi, Dewi Tryanasari, Edy Riyanto \\ Universitas PGRI MADIUN, Jalan Setia Budi 85 Madiun \\ Email: dtryanasari@gmail.com
}

\begin{abstract}
Problems schools that implement Curriculum 2013 in Magetan East Java is a teacher despite having been training Curriculum 2013 are still difficulties in developing thematic integrative learning device that refers to the scientific aproach. This study uses research development. The model chosen is a model development with consideration Adie simple step yet complete. Data extracted by open questionnaire and interview, after a teacher read a book, and then reflect on their understanding of the developing a learning device in Curriculum 2013. The results of data analysis known that the teacher's response is limited to books developed model is very good. Teachers stated that they understand the development of learning tools on the Curriculum 2013, especially in the scientific and thematic integrative approach.
\end{abstract}

Keywords: learning tools, curriculum 2013

\begin{abstract}
Abstrak: Permasalahan sekolah yang menerapkan Kurikulum 2013 di Kabupaten Magetan Jawa Timur adalah guru meskipun telah mengikuti pelatihan Kurikulum 2013 masih kesulitan dalam mengembangkan perangkat pembelajaran tematik integratif yang mengacu pada scientific aproach. Penelitian ini menggunakan penelitian pengembangan. Model pengembangan yang dipilih adalah model ADIE dengan pertimbangan langkah yang sederhana namun lengkap. Data digali dengan angket terbuka dan wawancara, setelah guru membaca buku, kemudian merefleksikan pemahamannya terhadap pengembagan perangkat pembelajaran Kurikulum 2013. Hasil analisis data diketahui bahwa respons guru secara terbatas terhadap buku model yang dikembangkan ialah sangat baik. Guru menyatakan bahwa mereka paham terhadap pengembangan perangkat pembelajaran pada Kurikulum 2013, terutama pada scientific approach dan tematik integratif.
\end{abstract}

Kata kunci: perangkat pembelajaran, kurikulum 2013

Kurikulum 2013 menekankan pada scientific aproach yang pada dasarnya menitikberatkan pada proses perolehan pengetahuan yang berbasis inquiry serta internalisasi pengetahuan secara mendalam dan bermakna yang berlangsung bertahap. Oleh karena itu, dalam Kurikulum 2013 aspek afektif, kognitif, dan psikomotor siswa dikembangkan secara holistik dan seiring sejalan. Curriculum system that applied by the school will be used as a reference by teachers in implementing the learning process (Gunawan, 2017). Imbas dari prinsip tersebut, pembelajaran tematik integratif di sekolah dasar (SD) dilaksanakan secara menyeluruh baik di kelas awal maupun di kelas lanjut. Pembelajaran tematik di SD bukanlah sesuatu yang sifatnya baru (Hidayat, 2013). Pembelajaran tematik pada
Kurikulum Tingkat Satuan Pendidikan (KTSP) diimplementasikan pada jenjang kelas bawah, yaitu kelas satu, dua, dan tiga namun untuk kelas tinggi SD masih menganut sistem tiap matapelajaran.

Berdasarkan hal itu, pelaksanaan Kurikulum 2013 di kelas tinggi yang saat ini diujicobakan pada kelas empat SD, harus mendapatkan perhatian yang lebih serius untuk mengantisipasi terjadinya kesalahan pemahaman di tingkat implementasi. Ada tujuh SD di Kabupaten Magetan yang ditunjuk sebagai sekolah pioner pelaksana Kurikulum 2013. Sekolah-sekolah tersebut tersebar pada wilayah Magetan bagian barat, timur, utara, dan selatan. Masing-masing sekolah tersebut melaksanakan uji coba kurikulum di bawah binaan Unit Pelaksana 
masing-masing, namun penelitian mendalam tentang keterlaksanaanya belum dipetakan. Untuk itu perlu dilakukan penelitian mendalam pada tujuh sekolah tersebut terkait dengan pelaksanaan Kurikulum 2013 terutama pada aspek scientific approach sebagai komponen pendekatan yang melandasi pembelajaran Kurikulum 2013.

Terkait dengan masalah yang ditemukan, dilakukan pengembangan buku model perangkat pembelajaran berbasis scientific approach sebagai suplemen guru dalam Kurikulum 2013. Buku yang dikembangkan berisi aspek teoritis scientific approach sebagai pendekatan yang digunakan pada Kurikulum 2013, teori tentang tematik integratif, serta implementasi keduanya dalam perangkat pembelajaran pada Kurikulum 2013. Perangkat pembelajaran Kurikulum 2013 yang dikembangkan oleh guru mengacu pada silabus yang telah dibuat oleh pusat. Oleh karena itu, implementasi scientific approach dan tematik integratif diwujudkan dalam Rencana Pelaksanaan Pembelajaran (RPP).

\section{METODE}

Penelitian ini menggunakan rancangan penelitian dan pengembangan (research and development). Model pengembangan yang dipilih adalah model ADIE dengan pertimbangan langkah yang sederhana namun lengkap (Arikunto, 2012). Data respons digali dengan angket terbuka dan wawancara setelah sebelumnya guru diminta untuk membaca secara detail buku model yang ada, kemudian merefleksikan pemahamannya terhadap pengembagan perangkat pembelajaran Kurikulum 2013 setelah membaca buku model tersebut.

The purpose of research and development is to bridge the gap that frequently exists between educational research and educational practice (Borg dan Gall, 2003). It is extremely important to note at this point however that science does not mean research and development, just as research and development does not equal innovation (Török, 2005). Selanjutnya pengembangan perangkat pembelajaran tersebut dituangkan dalam penelitian

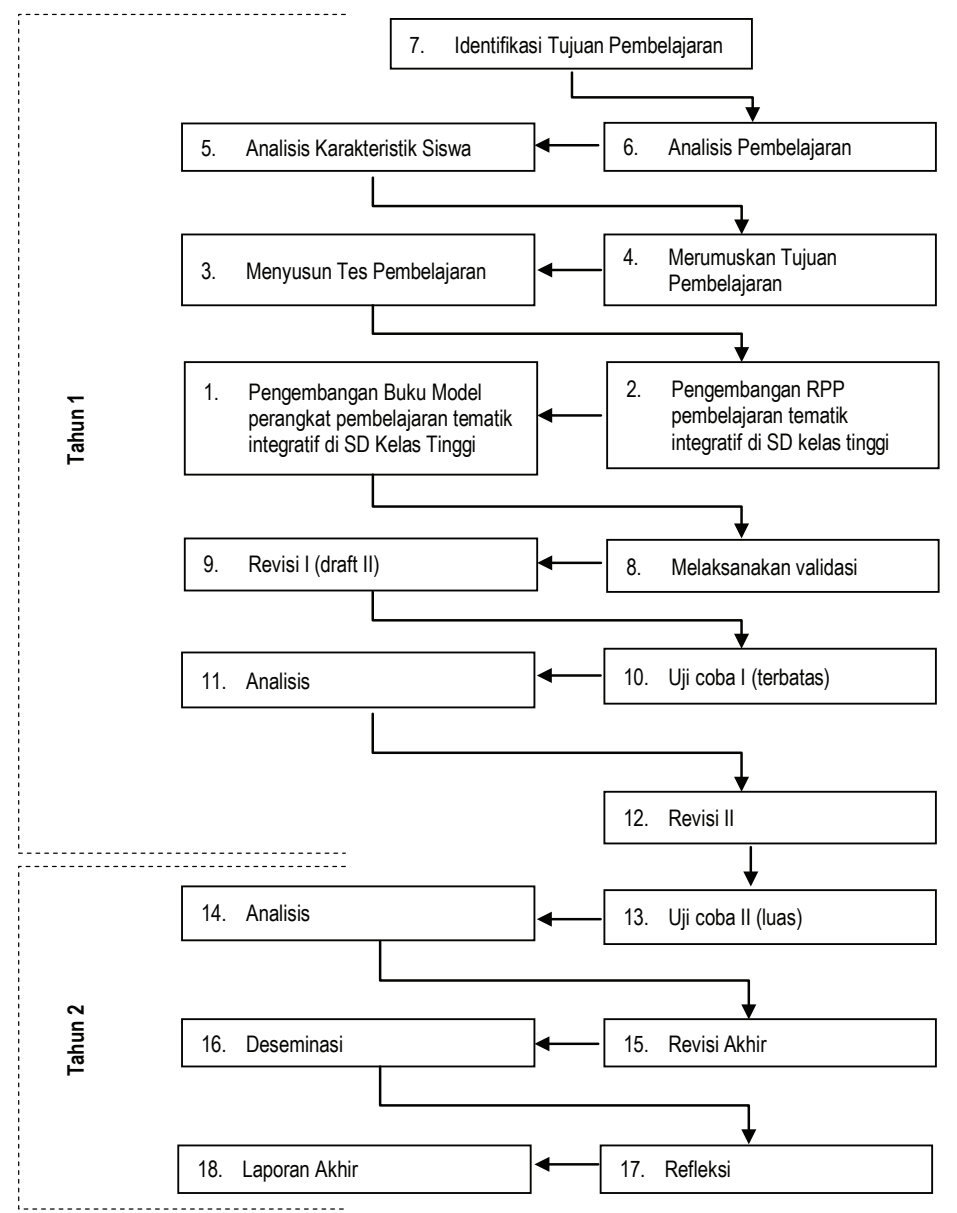

Gambar 1 Pengembangan Buku Model Perangkat Pembelajaran Tematik Integratif 
pengembangan Model Addie dengan langkah seperti yang diilustrasikan pada Gambar 1 .

Penggalian data dengan menggunakan instrumen sekunder berupa lembar respons seperti yang ditampilkan pada Tabel 1. Guru diminta memberikan respons terhadap buku yang telah disusun oleh tim pengembang. Respons guru tersebut dijadikan bahan pertimbingan revisi buku.

\section{HASIL}

Penelitian ini telah sampai pada tahap uji coba terbatas, di mana data tentang respons terbatas calon pengguna buku di lapangan diperoleh melalui lobservasi tidak langsung dengan memanfaatkan instrumen sekunder berupa lembar respons (Tabel 1). Berdasarkan hasil analisis data diketahui bahwa lima orang guru menyatakan sangat tertarik dengan buku model yang dikembangkan sedangkan dua orang menyatakan tertarik. Artinya dari segi kemenarikan dapat dikatakan bahwa buku model yang dikembangkan direspons dengan baik oleh guru pada tujuh sekolah pioner yang telah menerapkan Kurikulum 2013.

Sedangkan pada aspek kemudahan diperoleh data bahwa setelah membaca buku model yang dikembangkan, tujuh orang guru dari sekolah tersebut merasa lebih mudah dalam mengembangkan perangkat pembelajaran pada Kurikulum 2013. Hal ini sebab dalam buku model tersebut mereka dapat membandingkan antara contoh perangkat yang salah dengan contoh perangkat yang benar. Sayangnya analisis kesalahan perangkat yang salah tidak ditunjukkan secara detail sehingga guru harus mengecek sendiri bagian-bagian perangkat yang tidak sesuai dengan scientific approach.

Kegiatan pembelajaran Kurikulum 2013 mengacu pada scientific approach, yakni pembelajaran yang menitikberatkan pada pengembangan kemampuan siswa untuk mampu berpikir secara rasional, kritis, kreatif, ilmiah, dan berdasarkan pada kaidah keilmuan. Tabel 2 menampilkan kegiatan siswa dalam pembelajaran dengan pendekatan saintifik. Komponen yang terlibat dalam pengajaran adalah tujuan pembelajaran, materi pembelajaran, metode, alat, dan evaluasi. Prinsip-prinsip pembelajaran tersebut dituangkan dalam Permendiknas Nomor 41 Tahun 2007 tentang Standar Proses untuk Satuan Pendidikan Dasar dan Menengah.

\section{PEMBAHASAN}

Desain pembelajaran dikembangkan berdasarkan teori sistem. Penerapan teori sistem dalam pengembangan rencana pembelajaran adalah dikembangkannya komponen-komponen pengajaran secara sistematis dan terintegrasi (Hamalik, 2005). Kurikulum yang diterapkan oleh suatu bangsa akan mempengaruhi pelaksanaan pembelajaran yang dilakukan oleh guru dan siswa di kelas (Gunawan dan Benty, 2007). The integrative topics in some subjects in learning process as one of the main point in new Curriculum 2013 (Sahiruddin, 2013). The Curriculum 2013, which is to create productive, creative, innovative, through strengthening affective attitudes, skills, and integrated knowledge for Indonesians (Ramadhan dan Ramdani, 2015). The 2013 Curriculum is proposed to produce Indonesians who have religious tolerance and mental health; it is based

Tabel 1 Kisi-Kisi Lembar Respons Pengguna

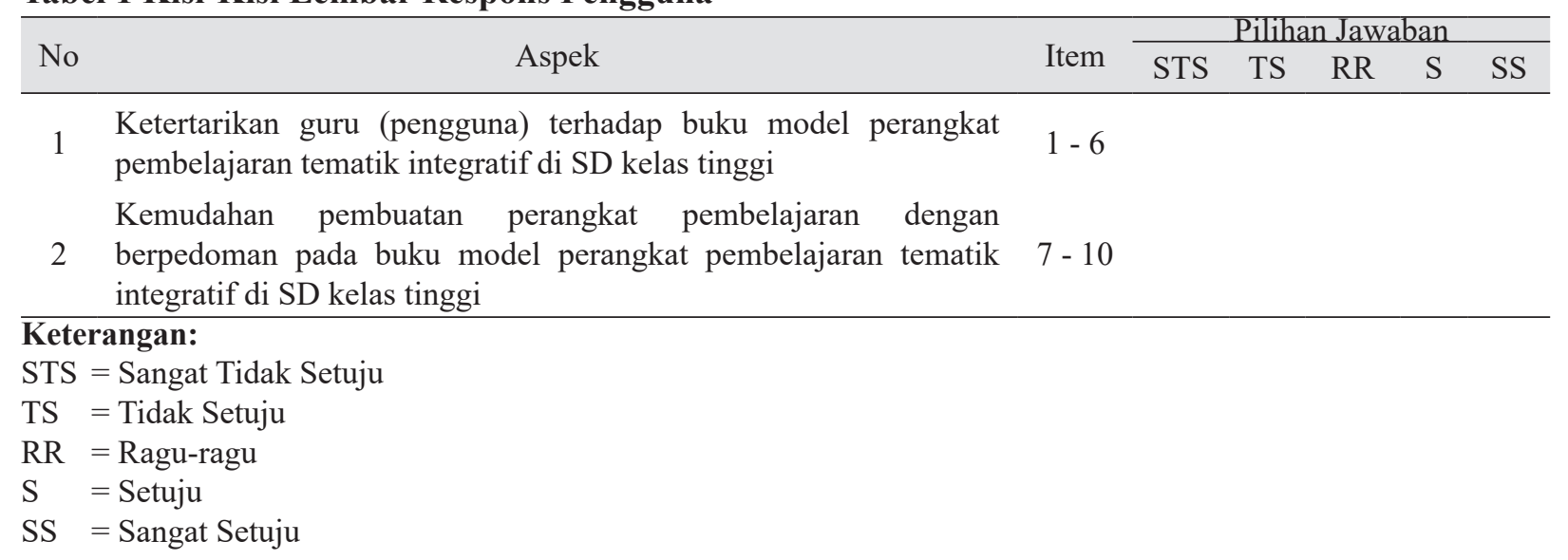




\section{Tabel 2 Kegiatan Siswa dalam Pembelajaran dengan Pendekatan Saintifik}

\begin{tabular}{|c|c|c|}
\hline No & $\begin{array}{c}\text { Langkah-langkah } \\
\text { Pendekatan Saintifik }\end{array}$ & Kegiatan Belajar \\
\hline 1 & Mengamati (observing) & $\begin{array}{l}\text { Melihat gambar / video, persitiwa / kejadian, benda nyata; mendengar cerita, } \\
\text { berita; membaca naskah, buku, berita; mencium bau; meraba suhu; mencicipi }\end{array}$ \\
\hline 2 & Menanya (questioning) & $\begin{array}{l}\text { rasa } \\
\text { Mengungkapkan ciri-ciri atau karakteristik obyek dari hasil pengamatan; } \\
\text { menanyakan sesuatu dari hasil pengamatan; berdialog saling tanya jawab; } \\
\text { melakukan perenungan; mengidentifikasi permasalahan; memberikan } \\
\text { tanggapan }\end{array}$ \\
\hline 3 & Menalar (associating) & $\begin{array}{l}\text { Mencari sebab akibat; menganalisis masalah; mencari perbedaan dan } \\
\text { persamaan; mencari hubungan; menganalisis kelebihan dan kekurangan; } \\
\text { menganalisis kekuatan dan kelemahan; membuat dugaan; membuat kesimpulan }\end{array}$ \\
\hline 4 & Mencipta & $\begin{array}{l}\text { Membuat dugaan/hipotesis/konjektur; merancang langkah percobaan; } \\
\text { membuat alat untuk percobaan }\end{array}$ \\
\hline 5 & $\begin{array}{l}\text { Mencoba } \\
\text { (experimenting) }\end{array}$ & $\begin{array}{l}\text { Melakukan simulasi; menjalankan peran; melakukan uji coba; membuat } \\
\text { rancangan; melaksanakan rencana; melakukan pengukuran; menguji hipotesis }\end{array}$ \\
\hline 6 & Menyaji & Mengkomunikasikan; memperagakan; memaparkan; melaporkan \\
\hline
\end{tabular}

on the fact that recently, a lot of young generation or students do not have character, tolerance and empathy for others anymore (Ningsih, 2016).

Proses pembelajaran dengan pendekatan saintifik bercirikan penonjolan pada dimensi pengamatan, penalaran, penemuan, pengabsahan, dan penjelasan tentang suatu kebenaran. Sehubungan dengan itu, beberapa ciri pendekatan saintifik dalam pembelajaran menurut Majid (2008) adalah: (1) materi pembelajaran berbasis pada fakta, gejala, atau peristiwa yang dapat diamati secara langsung atau pun tidak langsung dan dapat dijelaskan dengan logika atau penalaran tertentu, bukan sebatas kira-kira atau khayalan; (2) materi pembelajaran juga mengandung konsep dan teori yang dapat dipertanggungjawabkan; (3) penjelasan guru dan respons siswa terjadi secara obyektif dan logis serta bebas dari prasangka; (4) mendorong dan menginspirasi siswa berpikir secara kritis, analitis, obyektif, dan tepat dalam mengidentifikasi, memahami, memecahkan masalah, dan menerapkan materi pembelajaran; (5) mendorong dan menginspirasi siswa mampu berpikir hipotetik dalam melihat perbedaan, kesamaan, dan hubungan satu dengan yang lain dari materi pembelajaran; (6) mendorong dan menginspirasi peserta didik mampu memahami, menerapkan, dan mengembangkan pola berpikir yang rasional dan objektif dalam merespons substansi atau materi pembelajaran; (7) tujuan pembelajaran dirumuskan secara sederhana dan jelas, namun menarik sistem penyajiannya; (8) proses pembelajaran menyentuh tiga ranah, yaitu sikap, pengetahuan, dan keterampilan secara seimbang dan terpadu; dan (9) hasil akhir pembelajaran adalah peningkatan dan keseimbangan antara kemampuan untuk menjadi manusia yang baik (soft skills) dan manusia yang memiliki kecakapan dan pengetahuan untuk hidup secara layak (hard skills) dari siswa yang meliputi aspek kompetensi sikap, pengetahuan, dan keterampilan, sehingga menjadi siswa yang produktif, kreatif, dan inovatif.

Permendiknas Nomor 41 tahun 2007 tentang Standar Proses untuk Satuan Pendidikan Dasar dan Menengah menyatakan: (1) RPP dijabarkan dari silabus untuk mengarahkan kegiatan belajar peserta didik mencapai Kompetensi Dasar (KD); (2) setiap guru berkewajiban menyusun RPP secara lengkap dan sistematis agar pembelajaran berlangsung secara interaktif, inspiratif, menyenangkan, menantang, memotivasi peserta didik untuk berpartisipasi aktif, serta memberikan ruang yang cukup bagi prakarsa, kreativitas, dan kemandirian sesuai dengan bakat, minat, dan perkembangan fisik serta psikologis peserta didik; (3) RPP disusun untuk setiap KD dapat dilaksanakan dalam satu kali pertemuan atau lebih; guru merancang penggalan RPP untuk setiap pertemuan disesuaikan dengan penjadwalan di satuan pendidikan; dan (4) komponen RPP, meliputi identitas matapelajaran, standar kompetensi, kompetensi dasar, indikator pencapaian kompetensi, tujuan pembelajaran, materi ajar, alokasi waktu, metode pembelajaran, kegiatan pembelajaran, penilaian hasil belajar, dan sumber belajar.

Identitas matapelajaran, meliputi: satuan 
pendidikan, kelas, semester, program / program keahlian, matapelajaran atau tema pelajaran, jumlah pertemuan. Standar kompetensi merupakan kualifikasi kemampuan minimal peserta didik yang menggambarkan penguasaan pengetahuan, sikap, dan keterampilan yang diharapkan dicapai pada setiap kelas dan/atau semester pada suatu matapelajaran. Kompetensi dasar adalah sejumlah kemampuan yang harus dikuasai peserta didik dalam matapelajaran tertentu sebagai rujukan penyusunan indikator kompetensi dalam suatu pelajaran. Indikator kompetensi adalah perilaku yang dapat diukur dan/atau diobservasi untuk menunjukkan ketercapaian kompetensi dasar tertentu yang menjadi acuan penilaian matapelajaran. Indikator pencapaian kompetensi dirumuskan dengan menggunakan kata kerja operasional yang dapat diamati dan diukur, yang mencakup pengetahuan, sikap, dan keterampilan. Tujuan pembelajaran menggambarkan proses dan hasil belajar yang diharapkan dicapai oleh peserta didik sesuai dengan kompetensi dasar. Materi ajar memuat fakta, konsep, prinsip, dan prosedur yang relevan, dan ditulis dalam bentuk butir-butir sesuai dengan rumusan indikator pencapaian kompetensi. Alokasi waktu ditentukan sesuai dengan keperluan untuk pencapaian KD dan beban belajar.

Metode pembelajaran digunakan oleh guru untuk mewujudkan suasana belajar dan proses pembelajaran agar peserta didik mencapai kompetensi dasar atau seperangkat indikator yang telah ditetapkan (Sa'ud, 2008; Gunawan dan Sulistyoningrum, 2013). Pemilihan metode pembelajaran disesuaikan dengan situasi dan kondisi peserta didik, serta karakteristik dari setiap indikator dan kompetensi yang hendak dicapai pada setiap matapelajaran. Kegiatan pembelajaran meliputi pendahuluan, inti, dan penutup. Kurikulum yang dirancang harus dapat mengembangkan potensi siswa (Gunawan, 2015; Gunawan, 2017).

Pendahuluan merupakan kegiatan awal dalam suatu pertemuan pembelajaran yang ditujukan untuk membangkitkan motivasi dan memfokuskan perhatian peserta didik untuk berpartisipasi aktif dalam proses pembelajaran. Kegiatan inti merupakan proses pembelajaran untuk mencapai KD. Kegiatan pembelajaran dilakukan secara interaktif, inspiratif, menyenangkan, menantang, memotivasi peserta didik untuk berpartisipasi aktif, serta memberikan ruang yang cukup bagi prakarsa, kreativitas, dan kemandirian sesuai dengan bakat, minat, dan perkembangan fisik serta psikologis peserta didik. Kegiatan ini dilakukan secara sistematis dan sistemik melalui proses eksplorasi, elaborasi, dan konfirmasi. Penutup merupakan kegiatan yang dilakukan untuk mengakhiri aktivitas pembelajaran yang dapat dilakukan dalam bentuk rangkuman atau kesimpulan, penilaian dan refleksi, umpan balik, dan tindak lanjut. Prosedur dan instrumen penilaian proses dan hasil belajar disesuaikan dengan indikator pencapaian kompetensi dan mengacu kepada Standar Penilaian. Penentuan sumber belajar didasarkan pada standar kompetensi dan kompetensi dasar, serta materi ajar, kegiatan pembelajaran, dan indikator pencapaian kompetensi.

The teacher should be ready in the implementation the Curriculum 2013 in the teaching and learning activities, because it gives a greater influence in supporting the process of the curriculum is implemented (Arbie, 2015). The implementation of 2013 Curriculum will run well with the support of teachers/teachers staff (Khasanah, 2015). Successful instructional leaders work with other stakeholders to shape the purposes to fit the needs of the school and its environment (Hallinger, 2005). The new curriculum will focus on character development for elementary school students, skill development for junior high school and knowledge building for senior high school (The Jakarta Post, 2012). This is consistent with the spirit of Curriculum 2013, which prioritizes the affective values of students (Gunawan, 2016). Implementasi kurikulum dalam kegiatan pembelajaran di kelas oleh guru memerlukan seorang kepala sekolah yang mampu mengelola manajemen kurikulum dan pembelajaran secara andal (Gunawan, 2014).

\section{SIMPULAN DAN SARAN}

Berdasarkan analisis data disimpulkan bahwa respons guru terhadap buku model yang dikembangkan, pada tahap uji coba terbatas ialah sangat baik. Guru merasa terbantu untuk mengembangkan perangkat pembelajaran tematik integratif yang baik dengan berpedoman pada buku model yang dikembangkan. Mengacu pada hasil penelitian, saran yang diajukan bagi guru adalah 
merancang buku dan modul pembelajaran yang diampunya berdasarkan pendekatan ilmiah. Bagi kepala sekolah ialah agar melakukan supervisi pengajaran dengan pendekatan klinis, agar dapat membantu guru yang mengalami kesulitan dalam implementasi Kurikulum 2013. Bagi peneliti selanjutnya adalah harus menunjukkan detail kesalahan pada perangkat terdahulu yang sudah dihasilkan, sehingga guru lebih paham dengan analisis kesalahan perangkat yang sudah ada.

\section{DAFTAR RUJUKAN}

Arbie, S. 2015. The English Teachers' Perception of the Implementation Curriculum 2013 in SMK Negeri 1 Limboto, (Online), (http:// kim.ung.ac.id/index.php/KIMFSB/article/ download/7483/7373), diakes 2 Mei 2016.

Arikunto, S. 2012. Prosedur Penelitian: Suatu pendekatan Praktik. Jakarta: Rineka Cipta.

Borg, W. R., dan Gall., M. D. 2003. Educational Research: An Introduction. New York, London: Longman Inc.

Gunawan, I. 2014. Pengaruh Supervisi Pengajaran dan Kemampuan Guru Mengelola Kelas terhadap Motivasi Belajar Siswa. Ilmu Pendidikan Jurnal Kajian Teori dan Praktik Kependidikan, 41(1), 44-52.

Gunawan, I. 2015. Optimalisasi Peran dan Tugas Kepala Sekolah dalam Implementasi Kurikulum 2013. Prosiding Seminar Nasional Implementasi Kebijakan Ujian Nasional, Dualisme Kurikulum, dan Sistem Seleksi Masuk Perguruan Tinggi Negeri, Fakultas Ilmu Pendidikan Universitas Negeri Malang, 15 s.d. 16 Mei.

Gunawan,I. 2016. Model of EducationalLeadership in the Implementation of Curriculum 2013. Proceedings The $4^{\text {th }}$ International Conference Language, Society, and Culture in Asian Contexts (LSCAC 2016) on Cultivating and Casting Asian Diversities: Empowering the Asians, 24 s.d. 25 Mei.

Gunawan, I. 2017. Instructional Management in Indonesia: A Case Study. Journal of Arts, Science \& Commerce, 8(1), 99-107.

Gunawan, I., dan Benty, D. D. N. 2007. Musyawarah Guru Mata Pelajaran dan Kemampuan Mengelola Kelas untuk
Meningkatkan Motivasi Belajar Siswa. Manajemen Pendidikan, 20(1), 21-31.

Gunawan, I., dan Sulistyoningrum, R. T. 2013. Menggali Nilai-nilai Keunggulan Lokal Kesenian Reog Ponorogo Guna Mengembangkan Materi Keragaman Suku Bangsa dan Budaya pada Matapelajaran IPS Kelas IV Sekolah Dasar. Premiere Educandum, 3(1), 50-87.

Hallinger, P. 2005. Instructional Leadership and the School Principal: A Passing Fancy that Refuses to Fade Away. Leadership and Policy in Schools, 4: 1-20.

Hamalik, O. 2005. Kurikulum dan Pembelajaran. Jakarta: PT Bumi Aksara.

Hidayat, S. 2013. Pengembangan Kurikulum Baru. Bandung: Remaja Rosda Karya.

Khasanah, I. N. 2015. The Implementation of 2013 Curriculum by the English Teacher and its Barriers, (Online), (http://eprints.walisongo. ac.id/4572/1/113411021.pdf), diakses 20 Juni 2016.

Majid, A. 2008. Perencanaan Pembelajaran: Mengembangkan Standar Kompetensi Guru. Bandung: Remaja Rosda Karya.

Ningsih, N. A. 2016. The Issues of the Implementation of 2013 Curriculum in Teaching English at Junior High School Level. Proceedings The $4^{\text {th }}$ International Conference Language, Society, and Culture in Asian Contexts (LSCAC 2016) on Cultivating and Casting Asian Diversities: Empowering the Asians, Hotel Atria Malang, East Java, Indonesia, May 24-25, 2016.

Permendiknas Nomor 41 Tahun 2007 tentang Standar Proses untuk Satuan Pendidikan Dasar dan Menengah, (Online), (www. kemdikbud.go.id), diakses 2 Mei 2010.

Ramadhan, M. A., dan Ramdani, S. D. 2015. Vocational Education Perspective on Curriculum 2013 and its Role in Indonesia Economic Development, (Online), (http:// eprints.uny.ac.id/24449/1/A-19.pdf), diakses 3 Mei 2016.

Sahiruddin. 2013. The Implementation of the 2013 Curriculum and the Issues of English Language Teaching and Learning in Indonesia. Official Conference Proceedings - 
The Asian Conference on Language Learning 2013, pp. 567-574, (Online), (http://iafor. org/archives/offprints/acll2013-offprints/ ACLL2013_0362.pdf), diakses 12 Juni 2015. Sa'ud, S. 2008. Inovasi Pendidikan. Bandung: Alfabeta.

The Jakarta Post. 2012. Govt to Omit English from Primary Schools, (Online), (http://www. thejakartapost.com/news/2012/10/11/govtomit-english-primary-schools.html), diakses 6 Juli 2014.

Török, A. 2005. Competitiveness in Research and Development: Comparisons and Performance. Cheltenham, UK: Edward Elgar Publishing Limited. 